\title{
BMJ Open Radiographic features of importance in the National Institute for Occupational Safety and Health-administered Coal Workers' Health Surveillance Program: characterising the use of the 'other symbols'
}

\author{
Cara N Halldin, Janet M Hale, David J Blackley, A Scott Laney
}

To cite: Halldin CN, Hale JM, Blackley DJ, et al. Radiographic features of importance in the National Institute for Occupational Safety and Healthadministered Coal Workers' Health Surveillance Program: characterising the use of the 'other symbols'. BMJ Open 2017;7:e015876. doi:10.1136/ bmjopen-2017-015876

\section{- Prepublication history for} this paper is available online. To view these files, please visit the journal online (http://dx.doi. org/10.1136/bmjopen-2017015876).

Received 6 January 2017 Revised 3 July 2017 Accepted 10 July 2017

CrossMark

Respiratory Health Division, National Institute for Occupational Safety and Health, Morgantown, West Virginia, USA

Correspondence to

Dr Cara N Halldin;

challdin@cdc.gov

\section{ABSTRACT}

Objective The National Institute for Occupation Safety and Health-administered Coal Workers' Health Surveillance Program (CWHSP) provides radiographic pneumoconiosis screening for US coal miners. Radiographs are classified by readers according to International Labour Office criteria. In addition to pneumoconiotic parenchymal and pleural lung abnormalities, readers document radiographic features of importance (other symbols). Other symbols are not meant to imply a diagnosis or interpretation but are relevant as they provide information beyond a pneumoconiosis classification for features related to dust exposure and other aetiologies. Our objective was to summarise other symbol data from 48 years of CWHSP participants.

Methods Chest radiograph classifications obtained from CWHSP participants between July 1968 and July 2016 were analysed. Any 'other symbol' indication from any of the readings were counted. Frequencies were tabulated by individual reader and those identified by any reader.

Results Of the 469922 radiographs included in this study, nearly $15 \%$ had at least one reader identify a radiographic feature of importance. The most commonly identified other symbol was cancer (excluding mesothelioma) (6.83\%), followed by emphysema (1.68\%). Some features were rarely identified over the 48 years of data collection such as rheumatoid pneumoconiosis $(n=46)$, pneumothorax $(n=32)$, mesothelioma $(n=12)$ and rounded atelectasis $(n=4)$.

Conclusions This is the largest study to date describing radiographic features of importance as part of routine chest radiographic surveillance. While these symbols are not diagnostic they can be used to describe features associated with dust exposure. One of the most commonly identified radiographic features in our population is emphysema which is associated with respirable dust exposure. These results can be compared with other dust exposed populations.
Strengths and limitations of this study

- This is the largest study to date describing radiographic features of importance as part of routine chest radiographic surveillance.

- Results from this study can be used when evaluating radiographic features of other dust exposed populations.

- While not unexpected, inter-reader agreement was generally poor with the highest agreement being for cancer which might be expected given the population prevalence and gravity of the condition.

\section{INTRODUCTION}

The National Institute for Occupational Safety and Health (NIOSH) administers the Coal Workers' Health Surveillance Program (CWHSP) providing radiographic pneumoconiosis screening for US coal miners. According to the Federal Mine Safety and Health Act, radiographs are classified by readers according to International Labour Office (ILO) International Classification of Radiographs of Pneumoconioses. ${ }^{1}$ In addition to pneumoconiotic parenchymal and pleural lung abnormalities, readers document other radiographic findings under the 'other symbols' section of Chest Radiograph Classification form. Notation of other symbols, if features exist, is an obligatory requisite of a complete ILO classification. Other symbols are not meant to imply a diagnosis or interpretation but are relevant as they provide further information outside of a pneumoconiosis classification for suspected features related to dust exposure and other aetiologies.

In 1990, roughly 8 and $1 / 2$ years of data from the CWHSP were summarised with regard 
to 'other symbols' indicated during the first and second ILO classification of radiographs. ${ }^{2}$ Abnormal cardiac size or shape was most often identified followed by emphysema. Investigators demonstrated poor agreement between readers with respect to other symbols indicated during the ILO classification. Another study reviewed other symbols indicated during 10 years of the US Navy's Asbestos Medical Surveillance Program and found pleural thickening $(2.35 \%)$ and cardiac size or shape $(1.36 \%)$ to be the most commonly reported radiographic features. ${ }^{3}$ In this study, we sought to summarise other symbol data from 48 years of CWHSP participants.

\section{METHODS}

Chest radiograph ILO classifications obtained from CWHSP participants between July 1968 and July 2016 were analysed for any indication of the 28 possible 'other symbols'. Chest radiographs are classified by at least two (and up to five) physicians who have been trained or have demonstrated the ability to use the ILO pneumoconiosis classification system through the B Reader Certification Program administered by NIOSH. ${ }^{45}$ Physicians can become A Readers by attending a NIOSH-authorised course on the ILO classification system or by submitting examples of classifications to NIOSH for review. NIOSH B Reader certification requires demonstrating ongoing proficiency in the ILO classification system by passing a 6 hour examination and subsequent recertification examinations every 4 years thereafter. ${ }^{4}$ Prior to the CWHSP transition to digital radiography in 2012, the first ILO classification was usually completed by an A Reader at the local facility where the radiograph was obtained. Subsequent classifications were provided by NIOSH B Readers. Following 2012, new regulations required all classifications of digital chest images to be performed by B Readers. ${ }^{7}$ Therefore in this study, first readings are primarily from A Readers as they have provided the first readings for a majority of the programme's tenure. Second and subsequent readings have been done exclusively by B Readers.

SAS V.9.3 was used to tabulate the frequency of radiographic features indicated by other symbols, recorded by first reader only, second reader only, both the first and second reader and by any of up to five readers.

\section{RESULTS}

A total of 469922 radiographs with a valid ILO classification were evaluated for the presences of any 'other symbol' classification; at least one reader indicated the presence of a radiographic feature of importance in $68483(14 \%)$ radiographs. For the 469922 radiographs that were classified during the study period, the first reading was completed by an A Reader for $68.9 \%$ of radiographs $(\mathrm{n}=323966)$, with the remaining first readings $(n=145956)$ being conducted by B Readers. All second and subsequent classifications were completed by
B Readers only. A Readers performing the first reading identified at least one 'other symbol' among 33402 radiographs. B Readers who performed the first reading identified at least one 'other symbol' among 12105 radiographs.

'Cancer of the lung or pleura' was the most commonly identified feature (46.9\% of all radiographic features) identified in nearly $7 \%$ of the CWHSP radiographs (table 1). Emphysema was the second most commonly identified feature (11.5\% of all radiographic features) identified in $1.7 \%$ of CWHSP radiographs. The least often indicated symbols during classification were rheumatoid pneumoconiosis, pneumothorax, mesothelioma and rounded atelectasis, together accounting for less than 100 identified instances in the CWHSP.

Agreement between first and second reader, where both the first and second reader identified the feature, was poor ranging from $0 \%$ to $27.9 \%$ agreement depending on the other symbol indicated and $16.3 \%$ overall. Agreement was highest for cancer of lung or pleura $(27.9 \%)$ and calcified non-pneumoconiotic nodules or nodes (25.3\%). Aside from the most uncommonly identified features, agreement was the poorest for the identification of honeycomb lung (1.9\%).

\section{DISCUSSION}

The mandate of the CWHSP is to report on the respiratory health of US coal miners. This information is an important complement to the prevalence data that NIOSH regularly reports and are routinely used to assess prevalence and severity of coal workers' pneumoconiosis. In fact, NIOSH has made summary data publicly available through the CWHSP data query system. ${ }^{8}$ However, information on radiographic features of importance is not available and the only description of other symbols in the CWHSP was produced using 8 and $1 / 2$ years of data from the 1980s. Because indication of other symbols (if they are present) are a requisite of an ILO classification, it is important to examine and report these findings. Additionally information on these radiographic features may be used in statistical analyses to help explain variation between readers in their classification of the same radiograph.

This is the largest study to date describing radiographic features of importance as part of routine chest radiographic surveillance. While these symbols are not meant for diagnostic purposes, they can be used to describe radiographic features associated with dust exposure and/ or prompt clinical intervention in the case of features like cancer or tuberculosis. Emphysema, which is associated with respirable dust exposure, was one of the most commonly indicated symbols in our population. One of the least often indicated symbols was mesothelioma. As previously observed, inter-reader agreement was generally poor with the highest agreement being for cancer which might be expected given the population prevalence and gravity of the condition. Readers may be more 
Table 1 Frequency of 'other symbol' features of importance reported by first reader only, by second reader only, by both first and second reader, and by any reader* for 469922 chest radiographs taken in the Coal Workers' Health Surveillance Program between July 1968 and July 2016

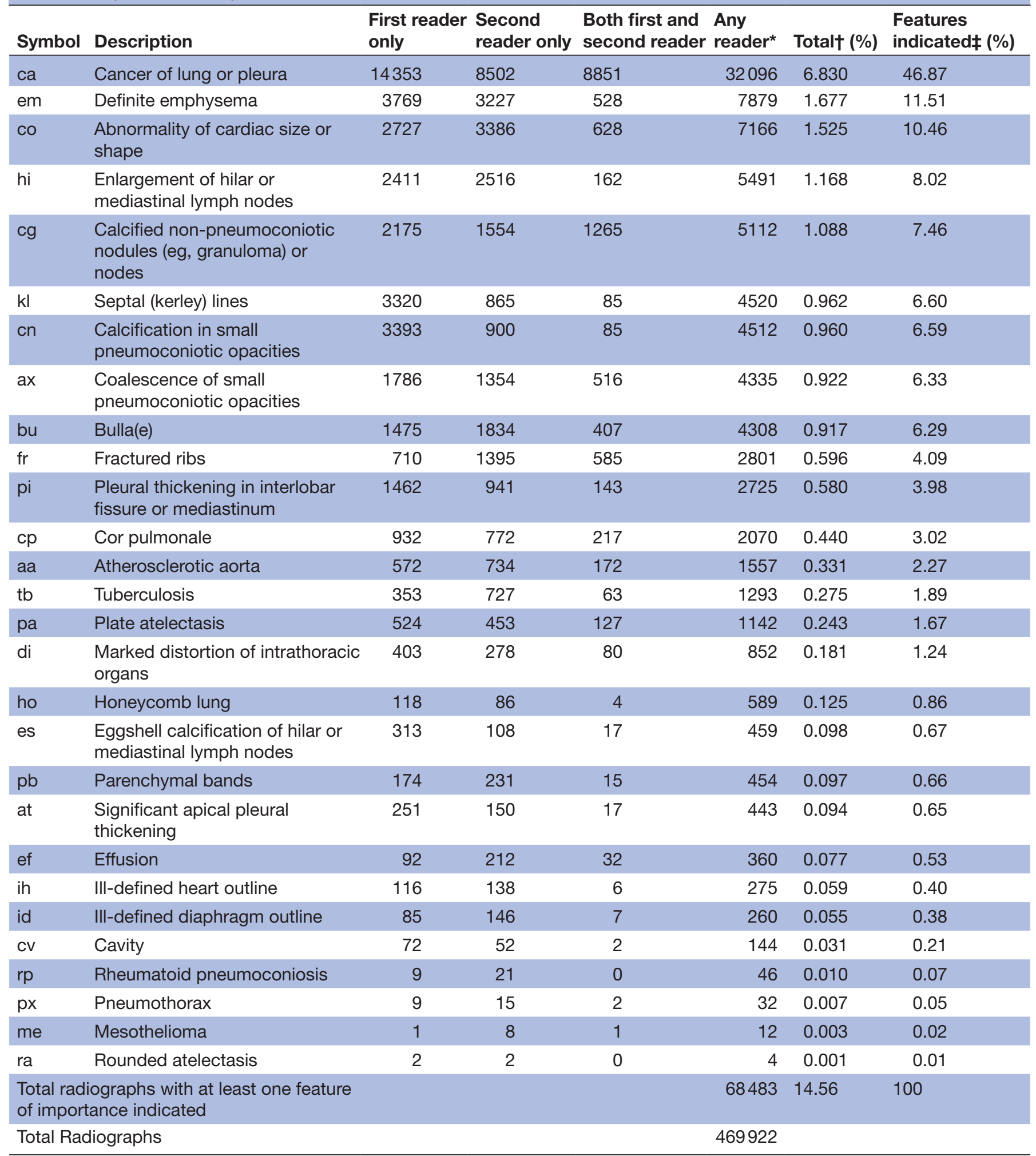

${ }^{*}$ Radiographs were read by up to five readers.

†Percentage calculated by dividing values in the 'Any reader' column by the total number of radiographs in this study ( $\mathrm{n}=469922)$. $\ddagger$ Percentage calculated by dividing values in 'Any reader' column by the total number of radiographs with at least one feature indicated $(n=68483)$. 
likely to indicate possible evidence to draw attention for immediate notification and primary care follow-up. First readings in this study were primarily conducted by A Readers as they have provided the first readings for a majority of the programme's tenure, whereas second readings were all done by B Readers. The poor inter-reader agreement observed in this study was not surprising as we recently demonstrated minimal agreement between $\mathrm{A}$ and B Readers with respect to film quality, presence of pneumoconiosis, small opacity profusion, and identification of pleural disease. ${ }^{9}$

When comparing to our findings, a report from the US Navy's Asbestos Medical Surveillance Program found similar prevalences of cardiac size/shape abnormalities $(1.36 \%$ vs $1.53 \%)$ and tuberculosis $(0.27 \%$ vs $0.28 \%)$ and a higher prevalence of fractured ribs $(1.24 \%$ vs $0.60 \%)$. Interestingly they found much lower prevalences of cancer $(0.56 \%$ vs $6.83 \%)$ and emphysema $(0.74 \%$ vs $1.68 \%)$, both of which are associated with tobacco smoke and dust exposure, however, neither exposure was assessed in the Navy's report and we are not able to quantify either exposure in our programme.

US coal workers are not the only population of dust-exposed workers for whom ILO radiographic classifications are performed. Though coal mining is a unique industry with specific exposure hazards, these results, using five decades of data, can potentially be used as an approximate baseline if investigators researching other dust-exposed populations (silica, cotton, asbestos, etc) have concerns regarding the prevalence of any of the other symbols in their population.

Acknowledgements The authors wish to acknowledge the contribution of $\mathrm{Dr}$ Robert Tallaksen, the NIOSH Coal Workers' Health Surveillance Program and the B Readers provided the ILO classifications used in this study.

Contributors $\mathrm{CNH}$ planned, analysed and interpreted the data and led writing the manuscript. JMH assisted with analysis and interpretation of the data. DJB and ASL assisted with interpreting data and writing the manuscript.

Funding There is no funding to report with this submission. The Centers for Disease Control (CDC), National Institute for Occupational Safety and Health (NIOSH) supported the salaries of the authors, and no other funding was obtained. This work was performed by Federal Government employees as part of their work; no non-governmental funding supported this work.

Competing interests None declared.

Patient consent Obtained.

Ethics approval National Institute for Occupational Safety and Health Human Subjects Review Board.

Provenance and peer review Not commissioned; externally peer reviewed. Data sharing statement No additional data are available.

Open Access This is an Open Access article distributed in accordance with the Creative Commons Attribution Non Commercial (CC BY-NC 4.0) license, which permits others to distribute, remix, adapt, build upon this work non-commercially, and license their derivative works on different terms, provided the original work is properly cited and the use is non-commercial. See: http://creativecommons.org/ licenses/by-nc/4.0/

(c) Article author(s) (or their employer(s) unless otherwise stated in the text of the article) 2017. All rights reserved. No commercial use is permitted unless otherwise expressly granted.

\section{REFERENCES}

1. International Labour Office. Guidelines for the use of the ILO international classification of radiographs of pneumoconioses. Geneva: International Labour Office, 2011.

2. Collet J, Castellan RM, Hodous TK, et al. Evaluation of a system recording non-pneumoconiotic abnormalities as part of coal worker's X-ray surveillance programme. Br J Ind Med 1990;47:647-8.

3. Muller JG, Bohnker BK, Philippi AF, et al. Trends in pleural radiographic findings in the Navy asbestos Medical Surveillance Program (1990-1999). Mil Med 2005;170:375-80.

4. Wagner GR, Attfield MD, Kennedy RD, et al. The NIOSH B reader certification program. an update report. J Occup Med 1992;34:879-84.

5. Centers for Disease Control and Prevention (CDC). Pneumoconiosis prevalence among working coal miners examined in federal chest radiograph surveillance programs--United States, 1996-2002. MMWR Morb Mortal Wkly Rep 2003;52:336-40.

6. Attfield MD, Wagner GR. A report on a workshop on the National Institute for Occupational Safety and Health B reader certification program. J Occup Med 1992;34:875-8.

7. Specifications for Medical Examinations of Underground Coal Miners". Title 42 Code of Federal Regulations, Pt. 37. 2014.

8. National Institute for Occupational Safety and Health. Coal Workers' Health Surveillance Program (CWHSP) Data Query System. https:// webappa.cdc.gov/ords/cwhsp-database.html (accessed 21 Nov 2016).

9. Halldin CN, Blackley DJ, Petsonk EL, et al. Pneumoconioses tadiographs in a large population of U.S. coal workers: variability in A Reader and B Reader classifications by using the International Labour Office classification. Radiology 2017:162437. 162437. 